\title{
The evidence-based medicine PICO strategy applied to dentistry using MeSH, Emtree and DeCS
}

\author{
Estrategia PICO de la medicina basada en la evidencia aplicada a \\ odontología con uso de los tesauros MeSH, Emtree y DeCS
}

\author{
María Teresa Alarcón-Gil ${ }^{1}$, Sonia Osorio Toro ${ }^{1}$, Gloria Patricia BaEna-Caldas ${ }^{1}$
}

TEBLAMI Research Group, School of Health, Universidad del Valle. Cali, Colombia

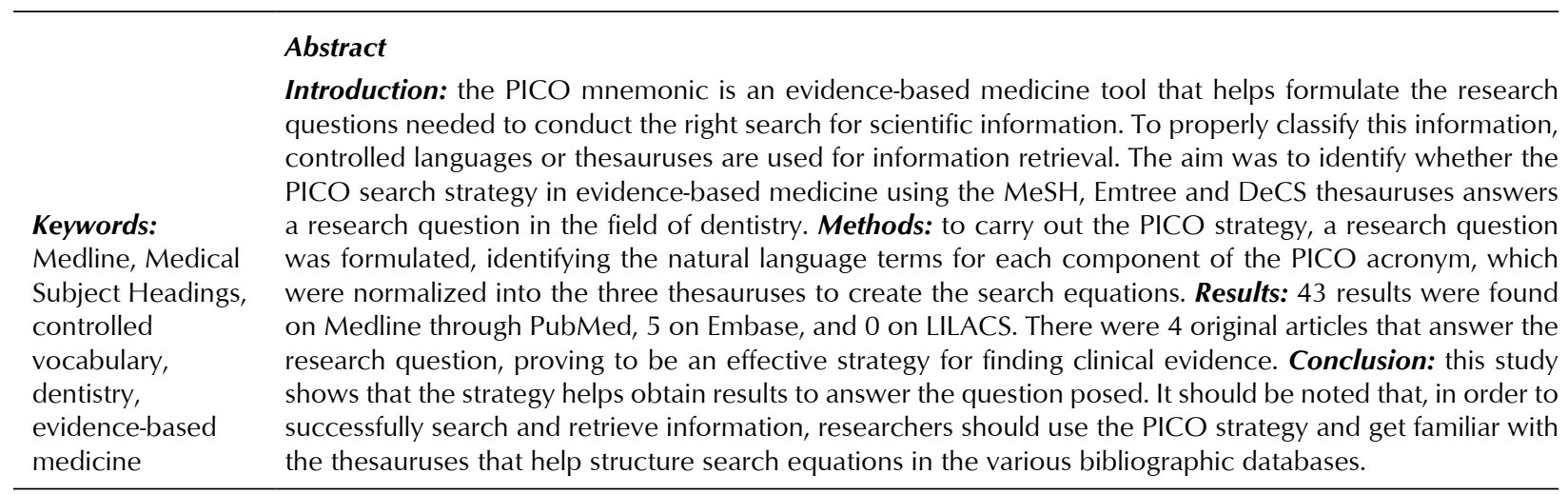

\section{Resumen}

Introducci n: la mnemotecnia PICO es una herramienta de la medicina basada en la evidencia que facilita la formulaci $n$ de preguntas de investigaci $n$ necesarias para realizar una correcta $b$ squeda de informaci $n$ cient fica. Para clasificar adecuadamente esta informaci $n$ se utilizan lenguajes controlados o tesauros que permiten ubicar dicha informaci n. El objetivo del presente estudio consisti en identificar si la estrategia de b squeda PICO de la medicina basada en la evidencia, utilizando los tesauros MeSH, Emtree y DeCS, responde a una pregunta de investigaci $\mathrm{n}$ en el campo de la odontolog a. $\boldsymbol{M}$ todos: para llevar a cabo la estrategia PICO, se elabor una pregunta de investigaci $n$, se identificaron los $t$ rminos en lenguaje natural para cada componente del acr nimo PICO, posteriormente se normalizaron en los tres tesauros y

Palabras clave: Medline, Medical Subject Headings, vocabulario controlado, odontolog a, medicina basada en la evidencia se construyeron las ecuaciones de b squeda. Resultados: se encontraron 43 resultados en Medline a trav s de la plataforma PubMed, 5 en Embase y 0 en LILACS. Se identificaron 4 art culos originales que responden la pregunta de investigaci $n$, demostrando ser una estrategia eficaz para la b squeda de evidencia $\mathrm{cl}$ nica. Conclusi n: el ejercicio realizado en el presente trabajo logr demostrar que la estrategia permite obtener resultados que responden a la pregunta planteada. Cabe resaltar que, para tener xito en la $b$ squeda $y$ obtenci $n$ de informaci $n$, los investigadores deber an utilizar la estrategia PICO y conocer los diferentes tesauros que facilitan la construcci $\mathrm{n}$ de las ecuaciones de b squeda en las diferentes bases de datos bibliogr ficas.

Submitted: December 19/2018 - Accepted: June 11/2019

How to quote this article: Alarc n-Gil MT, Osorio-Toro S, Baena-Caldas GP. The evidence-based medicine PICO strategy applied to dentistry using MeSH, Emtree and DeCS. Rev Fac Odontol Univ Antioq. 2019; 31(1-2): 91-101. DOI: http://dx.doi.org/10.17533/udea.rfo.v31n1-2a8 


\section{INTRODUCTION}

In ancient Greece, the great philosopher Socrates paved the way to a new philosophy through maieutics and thus challenged the sophists with the interrogative "What". Author William Betancourt states that this question opened for Socrates the means and character of reason and led him, slowly but continuously, to a new form of experience. ${ }^{1}$ Similarly, the first step of evidence-based medicine (EBM) is the formulation of a question, in order to start a learning process from the perspective of problem solving. The formulation of the right research question helps identify the appropriate keywords to perform the second step of EBM, or the search for information, in order to obtain relevant bibliographic resources. The third step is the critical analysis of the collected bibliographic information, and the fourth step is the use of results in clinical practice. ${ }^{2}$

The PICO strategy was first introduced by the Working Group of Evidence Based Medicine at McMaster University as an EBM tool that enables the construction of a well-focused question capable of resolving the queries raised in an interest's. PICO is an acronym in which the letter $P$ (Patient) stands for the problem to be solved or investigated in a patient or specific population; I (Intervention) is the intervention proposed for the solution of a question, such as a treatment, a diagnosis or a prognosis; C (Comparison group) is the comparison or intervention group with which it can be contrasted, and $\mathrm{O}$ (Outcome) refers to the expected result. $^{2}$

The keywords yielded by the question may correspond to terms in natural or colloquial language commonly used by health professionals; however, these terms are not recommended for systematic information search because some bibliographic databas- es use thesauruses to perform data analysis, a process that includes lists of standardized terms, also known as "descriptors". Once the descriptors that answer the research question are identified, they must be combined with Boolean connectors or logical operators in order to construct the search equation in the bibliographic databases, and thus obtain useful references that support the subject to be studied. It should be noted that Boolean connectors should always be capitalized; the most common are AND for combination, OR for addition, and NOT for exclusion. ${ }^{2}$

For additional accuracy in the information search process, controlled languages can be used to facilitate a specific bibliographic search; however, some researchers do not use them or are not aware of their existence. Following are the most relevant thesauruses in health sciences:

a. MeSH (Medical Subject Headings): this thesaurus was developed by the National Library of Medicine and consists of a list of controlled language terms used to describe the topic of Medline articles; it contains nearly 29,000 terms hierarchically organized by categories called trees. ${ }^{3}$

b. Emtree (Embase Subject Headings): this is a hierarchically structured and controlled lexicon for biomedicine and life sciences, developed by Elsevier for indexing articles in the Embase database; it includes more than 71,000 terms. In addition, the Embase database provides a default PICO form as a search option, which allows to integrate standard terms from this thesaurus. ${ }^{4}$

c. DeCS (Descriptors in Health Sciences): this thesaurus was created by BIREME to help indexing different types of 
materials, and for the search and retrieval of scientific literature in the information sources available in the Virtual Library in Health (VHL), including LILACS. It was developed from MeSH for searches in three languages; the concepts are hierarchically organized and include 33,558 descriptors and qualifiers, with 29,018 in MeSH and 4,540 exclusively in DeCS. $^{5}$

In order to develop an appropriate research question, it is important to take into account the objective of EBM, which seeks to accurately define the clinical problem, update the basic concepts, and conduct a critical analysis of data. ${ }^{2}$ This helps carry out more elaborate searches using thesauruses and filters, which is consistent with the search for specificity suggested by the PICO strategy. ${ }^{6}$

Another aspect to consider is the level of evidence from published research. The Grading of Recommendations, Assessment, Development and Evaluation (GRADE) proposes a more rigorous method for evidence categorization, both in the classification of evidence level as well as in degree allocation of recommendation for either preventive or therapeutic intervention as well as a diagnostic procedure directly related to the quality of evidence. According to GRADE, evidence can be classified into four categories: high, moderate, low and very low; however, this system provides a series of items that helps increase or reduce the quality level of the evidence initially assigned, as stated by Aguayo-Albasini et al. ${ }^{7}$ The high and moderate categories include studies in which there is a high to moderate confidence in the coincidence between actual and estimated effects, as in experimental studies such as randomized clinical trials; on the other hand, at the low and very low levels there is a limited or no confidence in the coincidence between actual and estimated effect, as is the case of observational studies, such as cohort studies and cases and controls. ${ }^{7}$

In consequence, studies with high to moderate levels of evidence are preferable; if such studies are not found, publications in the other two levels should be carefully taken. Specifically in the field of dentistry, the use of these tools become necessary because quality scientific information in this profession is scarce, and clinical experience seems to be the one that provides guidance in different interventions. ${ }^{7}$

Accordingly, the present study seeks to identify whether the EBM PICO strategy using the MeSH, Emtree and DeCS thesauruses answers a research question in the field of dentistry.

\section{METHODS}

The methodology to develop the PICO strategy in the field of dentistry used the following steps:

1. Preparation of the research question according to the PICO strategy.

2. Identification of all possible natural language synonyms to each component of the PICO tool.

3. Standardization of each natural language term with the respective thesauruses in bibliographic databases.

4. Adding descriptors to search builders of bibliographic databases, using Boolean connectors.

5. Selection of articles that answer the question posed, considering the levels 
of research evidence and recommended studies to be reviewed in a clinical diagnostic scenario.

6. Critical reading of articles that answer the initial research question.

For a brief explanation of the methodology used, an example is given with the research question posed, using a single term for each component of the PICO mnemonic in natural language as shown below.

In the first step, the following research question was posed: is there a concordance between clinical and imaging diagnoses for detecting a craniomandibular disorder, specifically disc displacement of the temporomandibular joint? This question corresponds to a search question model in a clinical diagnostic context. The study types recommended for this question are diagnostic tests, simple cross-sectional studies, comparative trials and systematic reviews. $^{2}$

Table 1 shows the natural language terms that were obtained by separating the question according to the PICO mnemonic.

Table 1. The PICO strategy in natural language

\begin{tabular}{|c|c|c|c|c|}
\hline \multirow{3}{*}{ Natural language } & \multicolumn{4}{|c|}{ Acronym } \\
\hline & Patient & Intervention & Comparison & Outcome \\
\hline & Craniomandibular Disorder & Clinical Diagnosis & Magnetic resonance imaging & Predictive Value \\
\hline
\end{tabular}

Source: by the authors

The terms used are described below:

\section{P: Craniomandibular Disorder}

For the PICO question posed in this study, the patient $(\mathrm{P})$ had a Craniomandibular Disorder or Temporomandibular Dysfunction (TMD), defined by the American Academy of Orofacial Pain (AAOP) as "a generic term encompassing a number of clinical problems affecting mastication muscles, temporomandibular joint (TMJ), associated structures or both."

\section{I: Clinical Diagnosis}

For the diagnostic test, disc position was assessed using findings from Research Diagnostic Criteria in Temporomandibular Disorders (RDC/TMD). ${ }^{10}$

\section{C: Magnetic Resonance}

The comparison was made against the Gold standard from the analysis of magnetic resonance (MR) of the TMJ. This is a specialized examination that uses magnetic fields and radiofrequency electromagnetic waves to observe soft tissues such as those found in the TMJ. ${ }^{11}$

\section{O: Predictive Value}

Positive predictive value is the clinical examination ability to provide a positive result to actual patients by making comparisons against imaging diagnosis, thus avoiding the inclusion of false positives. ${ }^{12}$ The expected outcome was a positive predictive value between clinical and imaging diagnosis to detect TMJ disc displacement. 
In the second step, all possible synonyms were identified in natural language for each component of the PICO mnemonic. In terms of $\mathrm{P}$, the most used synonyms were: craniomandibular dysfunction, temporomandibular dysfunction, temporomandibular disorder, craniocervicomandibular dysfunction. In the I component, the synonyms used were: clinical diagnosis, diagnosis, clinical examination, clinical evaluation. In $\mathrm{C}$, the synonyms were: magnetic resonance, diagnostic imaging, nuclear magnetic resonance, imaging diagnosis; finally, for the $\mathrm{O}$ component the synonyms were: predictive value, operational characteristics of the clinical test, and predictive value of the positive test.

To carry out the third step, each natural language term was normalized with the respective thesauruses present in different bibliographic databases: MEDLINE, Embase, Embase PICO search form (which for this study was accessed through the resources subscribed by the Universidad del Valle Library).

The fourth step involved combining the descriptors with Boolean connectors. These connectors allowed to restrict, extend or exclude information using keywords; ${ }^{13}$ for the PICO mnemonic, they were used as follows for each item:

P: first term OR second term

I: first term OR second term

C: first term OR second term

O: first term OR second term

After searching for each PICO mnemonic item using the OR connector, the Boolean AND connector was used between each semantic field as follows:
(The result of joining the two $\mathrm{P}$ terms) AND (The result of joining the two I terms) AND (The result of joining the two C terms) AND (The result of joining the two O terms). This may vary according to the number of terms used for each item, which may be one or more.

In the fifth step, the articles that answered the question were chosen.

Finally, the descriptors for each thesaurus were recorded in a table, including the stepby-step screenshots of the search process.

\section{RESULTS}

Below is a description of the search conducted using the PICO strategy in one of the proposed bibliographic databases, so that it can serve as a model for solving research questions in other areas of study.

\section{Search strategy in the Medline database through PubMed using the $\mathrm{MeSH}$ thesaurus}

The MeSH thesaurus in PubMed was accessed in order to identify the terms to be used. In some cases, MeSH may yield terms with names related to each other, so the researcher should look at the MeSH tree to identify hierarchies and refine the search. In the case of "Craniomandibular Disorders" as a patient-related term, it was decided to use the term "temporomandibular" as a keyword in $\mathrm{MeSH}$ in order to find more results related to this word, as this disorder is usually known by different names.

The search yielded 21 terms; however, at first glance it could be said that just five terms-temporomandibular joint disorders, temporomandibular joint disc, temporo- 
mandibular joint dysfunction syndrome, temporomandibular joint, craniomandibular disorders-were related to the subject of interest, but only the highest-ranking term was used in this exercise. By entering the descriptor, for example, "Temporomandibular Joint Disorders", one can observe its hierarchy within the MeSH tree, identifying that it comes from the term "Craniomandibular Disorders", which in turn derives the term "Temporomandibular Joint Dysfunction Syndrome". The highest-ranking terms show those below them, meaning that if you search for "Craniomandibular Disorders", the search results will include articles related to "Temporomandibular Joint Disorders" and "Temporomandibular Joint Dysfunction Syndrome" also.

In the case of "Temporomandibular Joint" and "Temporomandibular Joint Disc", the two terms are part of the "anatomy category" and derive from the descriptor "Joints", which refers to the anatomical structures that compose the TMJ in a normal state, which does not apply to the present search strategy as it is analyzing an alteration that depends directly on the "Diseases Category".
The PICO mnemonic development began with the search for the normalized Patient term. It was decided to use the "Craniomandibular Disorders" descriptor, which derives from the "Diseases Category" and is under the "Mandibular Diseases" descriptor (Figure 1).

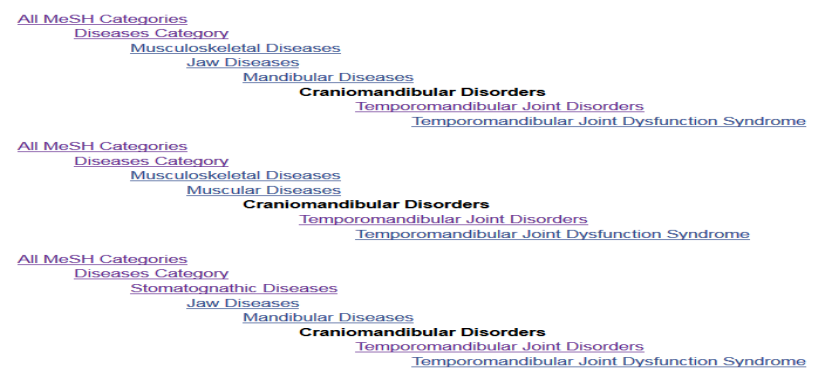

Figure 1. Hierarchy of the Craniomandibular Disorders descriptor. Source: PubMed - NCBI

Source: by the authors

Once Patient is identified, the term is added to the "PubMed Search Builder", running the "Search PubMed" option as shown in Figure 2, in order to find all the articles related to the normalized "Craniomandibular Disorders" term.

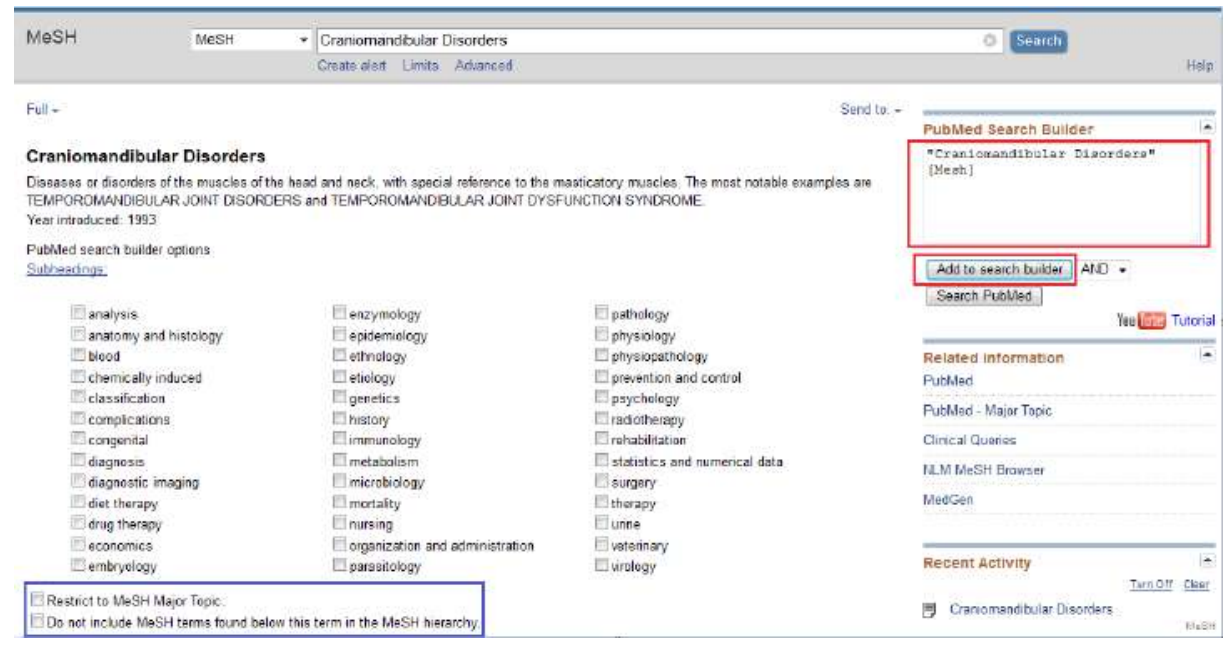

Figure 2. "Craniomandibular Disorders" Patient. Source: PubMed - NCBI

Source: by the authors 
Once this procedure was completed, the database searched for articles that were indexed under the term "Craniomandibular Disorders" and that had a direct relation to the topic of interest. A total of 16,199 results were found.

When the search was conducted without including normalized terms, the database conducted a mapping of the term in the $\mathrm{MeSH}$ field, and then searched for the phrase in all fields, as follows:
"Craniomandibular disorders" [MeSH Terms] OR ("craniomandibular" [All Fields] AND "disorders" [All Fields]) OR "craniomandibular disorders" [All Fields]

The terms for the other components of PICO mnemonics were searched in the MeSH thesaurus in the same way. After having normalized the four terms of each item belonging to the PICO, an advanced search was conducted. Each term was added to the "Builder" using the "History" option, hitting the "Search" bottom as shown in Figure 3.

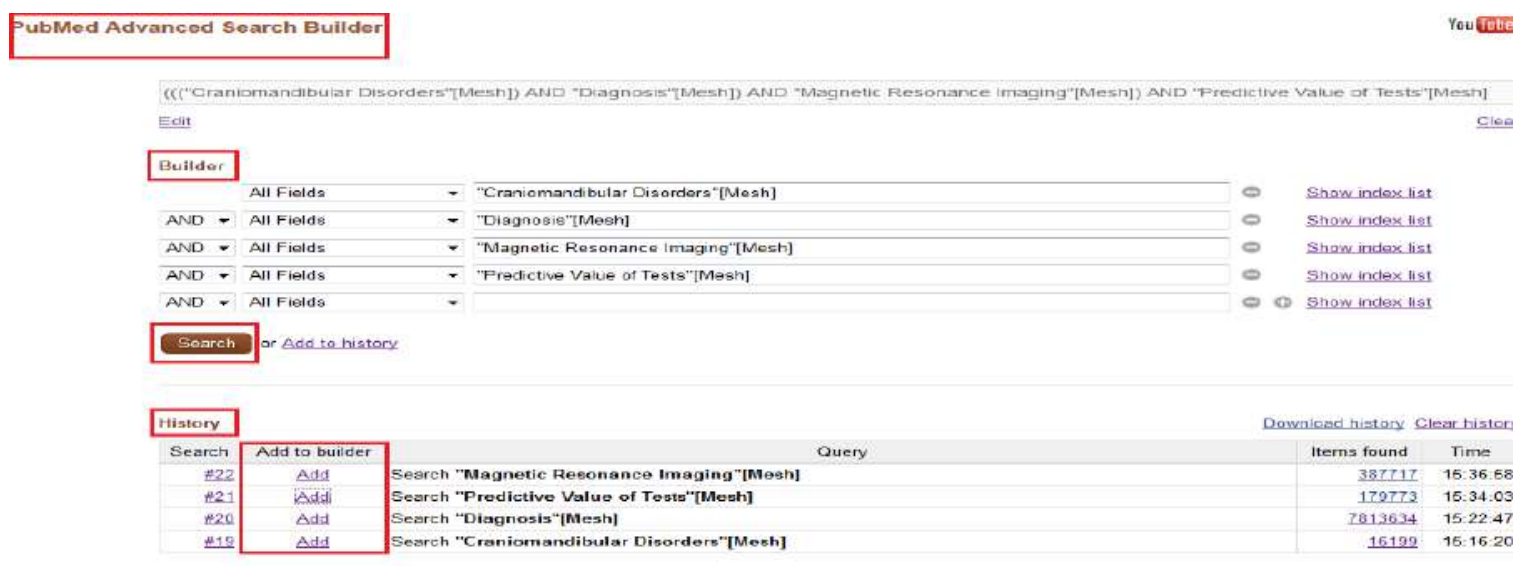

Figure 3. Construction of the search equation. Source: PubMed - NCBI

Source: by the authors

This procedure was followed by the construction of the search equation that answered the question posed according to the terms used. This equation yielded 43 articles.
The same process was later conducted in the EMBASE and LILACS bibliographic databases using the Emtree and DeCS thesauruses respectively. All results were listed in Table 2, with their respective search equations. 
Table 2. Summary of search results in the three bibliographic databases using thesauruses

\section{SEARCH LOG}

Is there concordance between clinical and imaging diagnoses for detecting a craniomandibular disorder, specifically disc displacement of the temporomandibular joint?

\begin{tabular}{|c|c|c|c|c|c|c|}
\hline \multirow[b]{2}{*}{ Thesaurus } & \multicolumn{4}{|c|}{ Acronym } & \multicolumn{2}{|l|}{ Search } \\
\hline & Patient & Intervention & Comparison & Outcome & Search equation & Results \\
\hline $\begin{array}{l}\text { Natural } \\
\text { language }\end{array}$ & $\begin{array}{l}\text { Craniomandibular } \\
\text { Disorder }\end{array}$ & $\begin{array}{l}\text { Clinical } \\
\text { diagnosis }\end{array}$ & $\begin{array}{l}\text { Magnetic } \\
\text { resonance }\end{array}$ & Predictive value & & \\
\hline MeSH & $\begin{array}{l}\text { Craniomandibular } \\
\text { Disorders }\end{array}$ & Diagnosis & $\begin{array}{l}\text { Magnetic } \\
\text { Resonance } \\
\text { Imaging }\end{array}$ & $\begin{array}{c}\text { Predictive Value } \\
\text { of Tests }\end{array}$ & $\begin{array}{c}\text { ((("Craniomandibular Disorders" [MeSH]) } \\
\text { AND "Diagnosis" [MeSH]) AND "Magnetic } \\
\text { Resonance Imaging"[MeSH]) AND "Predictive } \\
\text { Value of Tests"[MeSH] }\end{array}$ & 43 \\
\hline Emtree & $\begin{array}{l}\text { Temporomandibu- } \\
\text { lar Joint Disorder }\end{array}$ & Diagnosis & $\begin{array}{l}\text { Nuclear } \\
\text { magnetic } \\
\text { resonance } \\
\text { imaging }\end{array}$ & Predictive value & $\begin{array}{l}\text { 'temporomandibular joint disorder'/exp } \\
\text { AND 'diagnosis'/exp AND 'nuclear magnetic } \\
\text { resonance imaging'/exp AND 'predictive value'/ } \\
\qquad \exp \end{array}$ & 5 \\
\hline DeCS & $\begin{array}{c}\text { Craniomandibular } \\
\text { Disorders }\end{array}$ & Diagnosis & $\begin{array}{l}\text { Magnetic } \\
\text { Resonance } \\
\text { Imaging }\end{array}$ & $\begin{array}{l}\text { Predictive Test } \\
\text { Value }\end{array}$ & $\begin{array}{c}\text { Craniomandibular Disorders [Subject } \\
\text { Descriptor] and Diagnostics [Subject Descriptor] } \\
\text { and Magnetic Resonance Imaging AND } \\
\text { Predictive Test Value [Subject Descriptor] }\end{array}$ & 0 \\
\hline
\end{tabular}

Source: by the authors

The PICO mnemonic yielded 43 results in MEDLINE through PubMed and 14 results in Embase, of which 5 corresponded to the Embase database and 7 to MEDLINE, as Embase integrates the results of the MEDLINE database in its search. In addition, this same search strategy was carried out in the Embase PICO form, obtaining the same 14 results. On the other hand, no results were obtained on the LILACS database.

Finally, 4 original articles ${ }^{14-17}$ were identified that answer the research question posed in the field of dentistry.

\section{DISCUSSION}

Although few studies validate effectiveness of the PICO strategy, the exercise conducted in this study showed that the strategy pro- vides results that answer a research question in the field of dentistry.

The 4 identified original articles that answer a proposed research question include controversial results because some authors, such as Barclay et a $\mathrm{l}^{14}$ and Emshoff et $\mathrm{al}^{15}$ report a slight and low degree of concordance between both diagnosis techniques, concluding that the RDC/TMD instrument used for clinical diagnosis is limited in detecting TMJ disc position, and therefore it needs to be supplemented with MRI diagnosis. On the other hand, Manfredini et $\mathrm{al}^{16}$ and Kraus et al ${ }^{17}$ report a good level of concordance, showing that a complete medical history can correctly detect disc position alterations, while recognizing the importance of specialized examinations, as shown in Table 3. 
Table 3. Concordance between clinical and imaging diagnoses

\begin{tabular}{|c|c|c|}
\hline Study & Methods & Concordance \\
\hline $\begin{array}{c}\text { Barclay et al }{ }^{14} \\
1999 \\
\text { USA }\end{array}$ & $\begin{array}{c}\text { Instruments: } \\
\text { RDC/TMD- MRI 1.5 Teslas } \\
\text { Sample: } 78 \text { TMJs }\end{array}$ & $\begin{array}{c}K=0.36 \\
\text { Low concordance }\end{array}$ \\
\hline $\begin{array}{c}\text { Emsohoff et al15 } \\
2002 \\
\text { Austria }\end{array}$ & $\begin{array}{c}\text { Instruments: } \\
\text { RDC/TMD- MRI 1.5 Teslas } \\
\text { Sample: } 168 \text { TMJs }\end{array}$ & $\begin{array}{c}K=0.10 \\
\text { Slight concordance }\end{array}$ \\
\hline $\begin{array}{l}\text { Manfredini et al }{ }^{16} 2008 \\
\text { Italy }\end{array}$ & $\begin{array}{c}\text { Instruments: RDC/TMD - MRI } 1.5 \text { Teslas } \\
\text { Sample: } 232 \mathrm{TMJs}\end{array}$ & $\begin{array}{c}K=0.63 \\
\text { Good concordance }\end{array}$ \\
\hline Kraus et al ${ }^{17} 2017$ USA & $\begin{array}{c}\text { Instruments: RDC/TMD - MRI } \\
\text { Sample: } 92 \text { TMJ }\end{array}$ & $\begin{array}{c}K=0.80 \\
\text { Good concordance }\end{array}$ \\
\hline
\end{tabular}

Source: by the authors

This study did not find systematic reviews to allow a higher level of evidence of the consulted literature. The articles found are observational cross-sectional studies, which according to the evidence levels of the GRADE system show a low level of evidence. $^{7}$

However, the found information allows dental professionals to recognize that the clinical evaluation of the TMJ has a percentage of error, and definitive treatment cases should ideally rely on diagnostic evaluation through MRI, as patients with no intra-articular abnormalities may undergo unnecessary clinical-surgical interventions. In the case of conservative treatments, clinical examination alone may guide intervention plans, depending on alteration type.

This literature analysis was possible thanks to the PICO strategy, relying on automated databases that are excellent starting points for the search of scientific information. However, this search requires the acquisition of skills by researchers. ${ }^{18}$ More than 20,000 medical journals and 2,000,000 articles are published annually, requiring the design of indexing systems to facilitate their retrieval. ${ }^{19}$

Some authors argue that the PICO tool makes it easier to obtain the best available scientific information quickly and accurately; ${ }^{20}$ however, authors such as Schardt et $\mathrm{al}^{21}$ claim that a successful search using the PICO tool depends on the formulation of a successful research question. Nevertheless, there are few studies that assess the relevance of this tool. ${ }^{22}$

On the other hand, the authors of the present study consider that another important factor in the search for information is the researcher's expertise in the management of resources and knowledge of thesauruses, as the way of indexing information varies from one database to the other. The languagecontrolled search terms for MEDLINE (MeSH) and EMBASE (Emtree) are not identical, so it is important to specify searches according to the database used. In the present example, for instance, when the predictive value term was normalized in natural language in all three thesauruses, the MeSH term was "predictive value of tests", while the Emtree term was "predictive value" and in DeCS was "predictive test value".

\section{CONCLUSION}

The exercise carried out in this study showed that the PICO mnemonic helps obtain results to answer the clinical question posed 
regarding the concordance between clinical and imaging diagnoses to detect a TMJ disc displacement, as it was answered through studies found using the PICO strategy; therefore, the authors consider this to be a tool that makes it easier to find answers to research questions in the field of health, specifically in dentistry. On the other hand, taking into account the recommended types of study for questions in a clinical diagnostic scenario, appropriate cross-sectional, diagnostic and comparative studies were found.

\section{ACKNOWLEDGMENTS}

The authors of this article thank the Universidad del Valle Libraries Division for allowing the use of its electronic resources, and the TEBLAMI Research Group.

\section{CONFLICTS OF INTEREST}

The authors state that they have no conflict of interest.

\section{CORRESPONDING AUTHOR}

\author{
Mar a Teresa Alarc n-Gil \\ Universidad del Valle \\ (+572) 5185634 \\ maria.alarcon@correounivalle.edu.co \\ Calle 4B \# 36-00 \\ Biblioteca, edificio 122. Universidad del \\ Valle, Sede San Fernando \\ Cali. Colombia
}

\section{REFERENCES}

1. Betancourt Delgado W. Los caminos de Grecia en los or genes del pensar. Colombia: Universidad del Valle. Programa editorial. 2003.

2. Arceo D az JL, Ornela Aguirre JM, Dom nguez Salcido S. Manual de medicina basada en evidencias. M xico: Editorial El Manual moderno; 2010.

3. Fern ndez-Altuna MA, Mart nez del Prado A, Arriar n Rodr guez E, Guti rrez Ray n D, Toriz Castillo HA, Lifshitz Guinzberg A. Uso de los MeSH: una gu a pr ctica. Investigaci n en educaci n m dica. 2016; 5(20): 220-9.

4. Elsevier. A comparison of Emtree and MeSH. Amsterdam: Elsevier R\&D Solutions pharma \& life sciences, 2015.

5. Biblioteca Virtual en Salud. DeCS - Descriptores en ciencias de la salud. S o Paulo: biblioteca virtual en salud, 2018. Available in http://decs.bvs.br/E/decsweb2018.htm

6. Aromataris E, Riitano D. Constructing a search strategy and searching for evidence: a guide to the literature search for a systematic review. Am J Nurs. 2014; 114(5): 49-56. DOI: https://doi.org/10.1097/01. NAJ.0000446779.99522.f6

7. Aguayo-Albasini JL, Flores-Pastor B, Soria-Aledo V. [GRADE system: classification of quality of evidence and strength of recommendation]. Cir Esp. 2014; 92(2): 82-8. DOI: https://doi.org/10.1016/j.ciresp.2013.08.002

8. Solis G, Mercado SL. Odontolog a basada en evidencia: mitos, creencias y la realidad en nuestra carrera. Evid. Odontol. Clin. 2015; 1(1): 6-7. 
9. Ohrbach R, Dworkin SF. AAPT Diagnostic Criteria for Chronic Painful Temporomandibular Disorders. J Pain. 2019. DOI: https://doi.org/10.1016/j.jpain.2019.04.003

10. Schiffman E, Ohrbach R, Truelove E, Look J, Anderson G, Goulet JP, et al. Diagnostic criteria for temporomandibular disorders (DC/TMD) for clinical and research applications: recommendations of the International RDC/TMD Consortium Network and Orofacial Pain Special Interest Group. J Oral Facial Pain Headache. 2014; 28(1): 6-27. DOI: https://doi.org/10.11607/jop.1151

11. Orhan K, Aksoy S. Magnetic Resonance Imaging of TMJ. En: Rozylo-Kalinowska I, Orhan K. Imaging of the Temporomandibular Joint. Suiza: Springer, 2019. 155-204.

12. Carneiro AV. Diagnostic characteristics of tests: sensitivity, specificity, predictive values and likelihood ratios. Rev Port Cardiol. 2011; 30(5): 551-8.

13. D az Narv ez VP. Metodolog a de la investigaci $\mathrm{n}$ cient fica y bioestad stica: para $\mathrm{m}$ dicos, odont logos y estudiantes de ciencias de la salud. Chile: RiL editores, 2009.

14. Barclay P, Hollender LG, Maravilla KR, Truelove EL. Comparison of clinical and magnetic resonance imaging diagnosis in patients with disk displacement in the temporomandibular joint. Oral Surg Oral Med Oral Pathol Oral Radiol Endod. 1999; 88(1): 37-43.

15. Emshoff R, Brandlmaier I, Bosch R, Gerhard S, Rudisch A, Bertram S. Validation of the clinical diagnostic criteria for temporomandibular disorders for the diagnostic subgroup - disc derangement with reduction. J Oral Rehabil. 2002; 29(12): 1139-45.

16. Manfredini D, Guarda-Nardini L. Agreement between research diagnostic criteria for temporomandibular disorders and magnetic resonance diagnoses of temporomandibular disc displacement in a patient population. Int J Oral Maxillofac Surg. 2008; 37(7):612-6. DOI: https://doi.org/10.1016/j.ijom.2008.04.003

17. Kraus S, Prodoehl J. Disc displacement without reduction with limited opening: a clinical diagnostic accuracy study. Physiother Theory Pract. 2017; 33(3): 238-44. DOI: https://doi.org/10.1080/09593985. 2017.1288282

18. Campos-Asensio C. How to develop a bibliographic search strategy. Enferm Intensiva. 2018; 29(4): 182-6. DOI: https://doi.org/10.1016/j.enfi.2018.09.001

19. Jim nez Villa J, Argimon Pall s JM, Mart n ZA, Vilardell Tarr s M. Publicaci n cient fica biom dica: c mo escribir y publicar un art culo de investigaci n. Espa a: Elsevier; 2016.

20. Landa-Ram rez E, Arredondo-Pantale n AJ. Herramienta PICO para la formulaci $n$ y b squeda de preguntas cl nicamente relevantes en la psicooncolog a basada en la evidencia. Psicooncolog a. 2014; 11(2-3): 259. DOI: https://doi.org/10.5209/rev_PSIC.2014.v11.n2-3.47387

21. Schardt C, Adams MB, Owens T, Keitz S, Fontelo P. Utilization of the PICO framework to improve searching PubMed for clinical questions. BMC Med Inform Decis Mak. 2007; 7:16. DOI: https://doi. org/10.1186/1472-6947-7-16

22. Eriksen MB, Frandsen TF. The impact of patient, intervention, comparison, outcome (PICO) as a search strategy tool on literature search quality: a systematic review. J Med Libr Assoc. 2018; 106(4): 420-31. DOI: https://doi.org/10.5195/jmla.2018.345 